\title{
Acute Lung Injury: Time to Find a Way That Works
}

I have not failed. I've just found 10,000 ways that won't work.

Since the syndrome now known as acute lung injury (ALI) was first described over 40 years ago, enormous progress has been made in the clinical practice of critical care. Nonetheless, if they had the ability to look forward into the future, practitioners of that era might be shocked at the lack of evident progress in the treatment of this deadly disease. Indeed, 4 decades later, the most important advance in therapy that has effectively reduced mortality is a strategy of mechanical ventilation that avoids alveolar distension, ${ }^{1}$ which is not so much a therapy in itself as it is the avoidance of an iatrogenic injury. More recently, another study demonstrated a benefit in outcome associated with the administration of pharmacologic neuromuscular blockade. ${ }^{2}$ Somewhat unsatisfying, however, is the acknowledgment that the exact means of this benefit is unknown, except to say that it probably increases the chances for success of the first strategy-the avoidance of injury. Finally, a third therapy that involves aggressive fluid removal from the patient has been shown to reduce the duration of mechanical ventilation, ${ }^{3}$ a prospect that seems heartening but for the fact that much if not most of that fluid is given to the patients by us in the first place. In essence, these "therapies" share a common theme: that we should support the patient, attempt to avoid doing them harm, and allow their ravaged lungs to heal on their own, if they can.

Meanwhile, the road to this point has been littered with failed therapies. Aside from the success of low-tidal-volume ventilation, the litany of apparently ineffectual ventilators and ventilation strategies is long and includes therapies as esoteric as liquid perfluorocarbon ventilation and as seemingly mundane as laying the patient on his stomach instead of on his back. Likewise, pharmacologic strategies have been equally disappointing, from the bluntest efforts to use high-dose corticosteroids to suppress immunity, to the most precisely targeted compounds, which have aimed, scalpel-like, to excise specific steps in the cascade of immune regulation. Our failures share a common theme as well: they sought to arrest or reverse progression of the disease after onset.

In this issue of RESPIRATORy CARE, Shari and colleagues describe findings that suggest an alternative approach may be more fruitful. In their study of patients with ALI who presented to the Mayo Clinic intensive care units ${ }^{4}$ they found that the majority of patients developed ALI while already admitted to the hospital, and moreover that the median time to development of ALI in these patients was 30 hours after hospital admission. Of those who presented with "community-acquired" ALI, the majority had recently come into contact with the healthcare system as out-patients prior to presenting to the hospital. As Shari et al note, these data suggest that there may be a brief but crucial time interval in which interventions might be instituted to prevent ALI. We already know that this disease can be prevented, at least in part; a prior study at the same institution demonstrated that restricting blood-product transfusions and limiting mechanical ventilator tidal volume decreased the incidence of ALI among patients at risk. ${ }^{5}$ Other recent work has attempted to identify factors in this patient population that might enable earlier prediction of factors associated with lung injury, and hence perhaps allow earlier institution of preventive measures. ${ }^{6}$

See the Original Study on Page 576

A new approach for dealing with ALI is desperately needed. Perhaps most disheartening is the fact that the few advances we have made do not appear to have meaningfully impacted the mortality rate. ${ }^{7}$ Further efforts into studying treatments for already-extant ALI will no doubt continue, but based on collective past experience, the potential that therapies aimed at the immune system or at mechanical ventilation strategies will be efficacious seems to be modest at best. Other promising novel therapies, such as mesenchymal stem-cell transplant, are still far from being ready for clinical use. However, preventive strategies can be quickly and cheaply deployed by implementing protocols, some of which we already know are effective. As Shari and colleagues point out, ${ }^{4}$ for many of these patients we may have a critical window in which we can intervene, before the onset of a disease in which our best therapies to date essentially involve supporting the patient until the condition resolves on its own. In short, the time is ripe for a new paradigm: a way that works.

Ednan K Bajwa MD MPH

Pulmonary and Critical Care Unit Massachusetts General Hospital Boston, Massachusetts 


\section{Acute Lung Injury: Time to Find a Way That Works}

\section{REFERENCES}

1. NHLBI Acute Respiratory Distress Syndrome Network. Ventilation with lower tidal volumes as compared with traditional tidal volumes for acute respiratory distress syndrome. New Engl J Med 2000;342(18): 1301-1308.

2. Papazian L, Forel JM, Gacouin A, Penot-Ragon C, Perrin G, Loundou A, et al; ACURASYS Study Investigators. Neuromuscular blockers in early acute respiratory distress syndrome. New Engl J Med 2010; 363(12):1107-1116.

3. National Heart, Lung, and Blood Institute Acute Respiratory Distress Syndrome (ARDS) Clinical Trials Network, Wiedemann HP, Wheeler

The author has disclosed no conflicts of interest.

Correspondence: Ednan K Bajwa MD MPH, Pulmonary and Critical Care Unit, Massachusetts General Hospital, Boston MA 02114. E-mail: ebajwa@partners.org.

DOI: $10.4187 /$ respcare. 01350
AP, Bernard GR, Thompson BT, Hayden D, deBoisblanc B, Connors AF Jr, Hite RD, Harabin AL. Comparison of 2 fluid-management strategies in acute lung injury. New Engl J Med 2006;354(24):25642575.

4. Shari G, Kojicic M, Li G, Cartin-Ceba R, Trillo Alvarez C, Kashyap $\mathrm{R}$, et al. Timing of the onset of acute respiratory distress syndrome: a population-based study. Respir Care 2011;56(5):576-582.

5. Yilmaz M, Keegan MT, Iscimen R, Afessa B, Buck CF, Hubmayr $\mathrm{RD}$, Gajic O. Toward the prevention of acute lung injury: protocolguided limitation of large tidal volume ventilation and inappropriate transfusion. Crit Care Med 2007;35(7):1660-1667.

6. Gajic O, Dabbagh O, Park PK, Adesanya A, Chang SY, Hou P, et al; United States Critical Illness and Injury Trials Group: Lung Injury Prevention Study Investigators. Early identification of patients at risk of acute lung injury: evaluation of lung injury prediction score in a multicenter cohort study. Am J Respir Crit Care Med 2011;183(4): 462-470.

7. Phua J, Badia JR, Adhikari NK, Friedrich JO, Fowler RA, Singh JM, et al. Has mortality from acute respiratory distress syndrome decreased over time? A systematic review. Am J Respir Crit Care Med 2009;179(3):220-227. 